\title{
Mine schedule optimisation with ventilation constraints: a case study
}

\author{
H Zhang MIRARCO Mining Innovation, Canada \\ R Hauta MIRARCO Mining Innovation, Canada \\ L Fava MIRARCO Mining Innovation, Canada
}

\begin{abstract}
This paper describes a process for optimising mine schedules with ventilation constraints using the Schedule Optimization Tool (SOT), the Ventilation Constraint Module (VCM) and a ventilation network solver (Ventsim). The VCM was developed as a component of MIRARCO's SOT+ research project.

Proper ventilation is critical for underground mines to operate safely, yet it is often not adequately considered early in the mine planning cycle. The need to account for ventilation early in the long-term planning cycle motivated the development of the VCM. The VCM generates constraints on the schedule of mining activities for each zone and for each stage of the mine life, based on available airflows. These constraints are intended to ensure that a mine schedule will be feasible from a ventilation perspective. Adhering to these ventilation-based constraints, as well as other constraints related to the project, SOT maximises the net present value (NPV) of the long-term schedule. The VCM will also assist the user in identifying opportunities to redistribute the airflow in the mine in ways that support higher-NPV schedules.
\end{abstract}

A case study for a hypothetical underground mine will be presented, showing that the VCM supports the generation of optimised life-of-mine schedules that adhere to realistic ventilation constraints.

Keywords: mine schedule optimisation, ventilation, Ventilation Constraint Module, Schedule Optimization Tool, mine planning

\section{Introduction}

A mine ventilation system clears contaminants out of an underground mine, providing fresh air to workers and equipment. In general, ventilation accounts for 35 to $50 \%$ of the total energy cost for an underground mine (Allen \& Tran 2011; Hardcastle et al. 2007). For metal and non-metal underground mines, the ventilation system is mainly used for diluting the concentration of harmful gases such as diesel particulate matter (DPM) and dust below regulatory limits, and for cooling the air.

Since adequate ventilation is necessary for safe underground mining, accounting for ventilation constraints early in the mine planning cycle can have significant benefits. In particular, a feasible schedule with maximised net present value (NPV) can be generated due to the simultaneous optimisation of the ventilation system and the long-term schedule. Currently, there is no commercial mine scheduling software package that explicitly accounts for ventilation constraints in the schedule optimisation process.

The VCM has been developed by MIRARCO as part of the SOT+ research project. Two other software modules have been developed within the project, namely the GeoSequencing Module and the Advanced Valuation Module (AVM). The GeoSequencing Module generates geotechnically motivated scheduling constraints, while the AVM implements processes for generating robust optimised schedules that account for product price and ore grade uncertainties. 


\section{Ventilation Constraint Module}

\subsection{Components of the Ventilation Constraint Module}

The VCM software consists of two components: the Ventilation District Generator and the Ventilation Constraint Generator. This section explains the functionality of each of these components.

A ventilation district is a group of mining activities that share the same intake air. A mining activity represents a task that must occur within a long-term underground mine schedule. Establishing ventilation districts is a preliminary step towards being able to ensure, for example, that at any point in the mine life, the activities at any given location will be constrained to what can be adequately ventilated. Given a mine layout and a preliminary life-of-mine (LOM) schedule, the Ventilation District Generator defines ventilation districts.

A trigger activity is defined as an activity that will dramatically change the airflow in one or more ventilation districts when an activity is complete, for example, when a ventilation raise breaks through. For a given mine layout, with defined ventilation districts and trigger activities, a ventilation scenario is comprised of a set of device settings over the stages of the mine life. Equivalently, it is a set of airflows over the stages of the mine life. The relevant devices typically include regulators and fans with variable speed drives.

The Ventilation Constraint Generator takes input specific to the ventilation scenario into account:

- The initial airflow in each ventilation district and the airflow changes, positive or negative, in the ventilation districts resulting from completion of the trigger activities. In the example shown in Table 1, after the completion of trigger activities 1 and 2, the total airflow quantity in ventilation district 1 becomes $35.4 \mathrm{~m}^{3} / \mathrm{s}$. These values are obtained through integration with a ventilation solver.

- Airflow requirements for equipment and crews working in the mine. For example, Table 2 indicates that a load-haul-dump machine (LHD) requires $18.88 \mathrm{~m}^{3} / \mathrm{s}$ of fresh air to operate.

Using this information, the Ventilation Constraint Generator creates equipment constraints for the ventilation districts over the stages of the mine life.

Table 1 Example of ventilation district airflow data

\begin{tabular}{lllll}
\hline \multirow{2}{*}{$\begin{array}{l}\text { Ventilation } \\
\text { district }\end{array}$} & $\begin{array}{l}\text { Initial airflow } \\
\left(\mathbf{m}^{3} / \mathrm{s}\right)\end{array}$ & \multicolumn{3}{c}{ Change in airflow $\left(\mathbf{m}^{3} / \mathbf{s}\right)$} \\
\cline { 3 - 5 } & Trigger activity $\mathbf{1}$ & Trigger activity $\mathbf{2}$ & Trigger activity $\mathbf{3}$ \\
\hline 1 & 9.44 & 37.76 & -11.80 & -11.80 \\
2 & 9.44 & 25.96 & 11.80 & -11.80 \\
3 & 4.72 & 0 & 0 & 21.24 \\
\hline
\end{tabular}

Table 2 Example of equipment airflow requirements

\begin{tabular}{ll}
\hline Equipment & Airflow requirements $\left(\mathrm{m}^{3} / \mathrm{s}\right)$ \\
\hline LHD & 18.88 \\
Grader & 6.60 \\
Truck & 33.04 \\
\hline
\end{tabular}

The VCM has been integrated with the Schedule Optimization Tool (SOT) (Fava et al. 2013) and Ventsim (Chasm Consulting 2016). The VCM interacts with Ventsim to generate ventilation districts, ventilation scenarios and equipment constraints. SOT then optimises the NPV of the LOM schedule while adhering to these equipment constraints. 


\subsection{Workflow for the Ventilation Constraint Module}

The VCM workflow is shown in Figure 1. The VCM is integrated with SOT to embed the ventilation constraints into the schedule optimisation process. SOT is a commercialised schedule optimiser, which uses a genetic algorithm and customised heuristics to rearrange the activities in the long-term schedule to achieve higher-NPV yet feasible schedules (Fava et al. 2013). The SOT-optimised schedules adhere to all pre-defined operational resource constraints and precedence constraints.

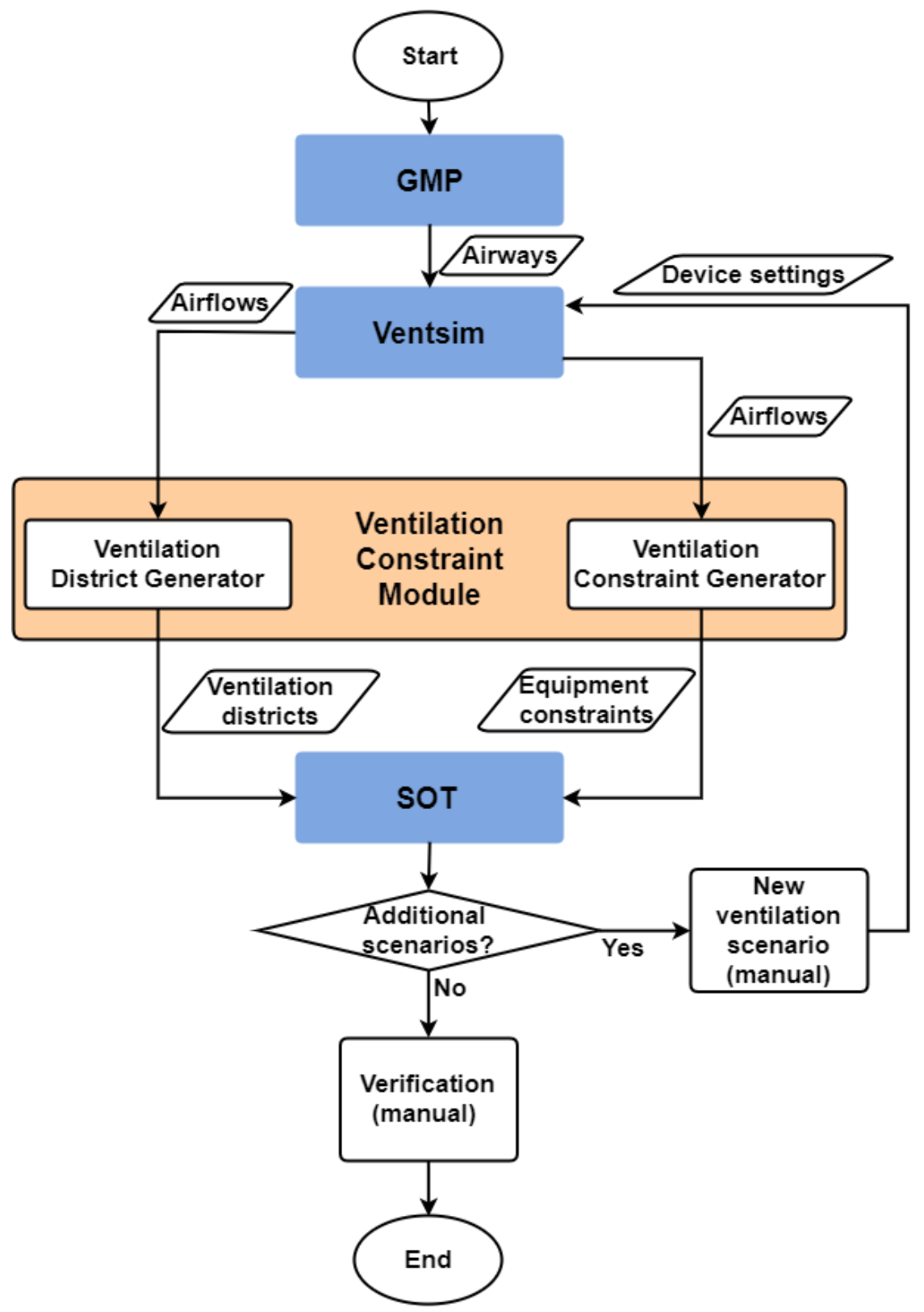

Figure 1 The VCM workflow

A mine layout is designed in a general mine planning (GMP) software package, with centrelines that have activity identifiers and airway geometry attributes that are required for automatic export to Ventsim. With the exported airways, the user completes the Ventsim model by inserting and configuring control devices such as fans and regulators; this defines the initial ventilation scenario. 
The Ventilation District Generator interacts with Ventsim to identify the trigger activities and the ventilation districts based on the airflow distributions for the ventilation scenario. The Ventilation Constraint Generator produces airflow-based equipment constraints for each ventilation district, and SOT then generates NPVoptimised schedules adhering to all the equipment constraints.

The user may generate additional ventilation scenarios by changing device settings in Ventsim; by repeating this process several times, the generated ventilation scenario that supports the highest-NPV schedule will be identified. The ventilation scenario and the optimised schedule can then be reviewed in Ventsim and the GMP software by the user.

\section{Case study}

The primary objective of this case study is to validate the workflow and functionality of the Ventilation Constraint Module. A secondary objective is to assess the effects of ventilation constraints applied to the schedule optimisation process.

\subsection{Hypothetical mine design}

A hypothetical underground nickel and copper mine was designed in Deswik.CAD (Deswik Mining Consultants (Australia) Pty Ltd 2014). The mining method applied is primary-secondary bottom-up open stoping. There are ten levels in the mine as shown in Figure 2. There are 19 trigger activities and 24 ventilation districts in this mine, as shown in Figure 3. The trigger activities are the last segments of ventilation raises.

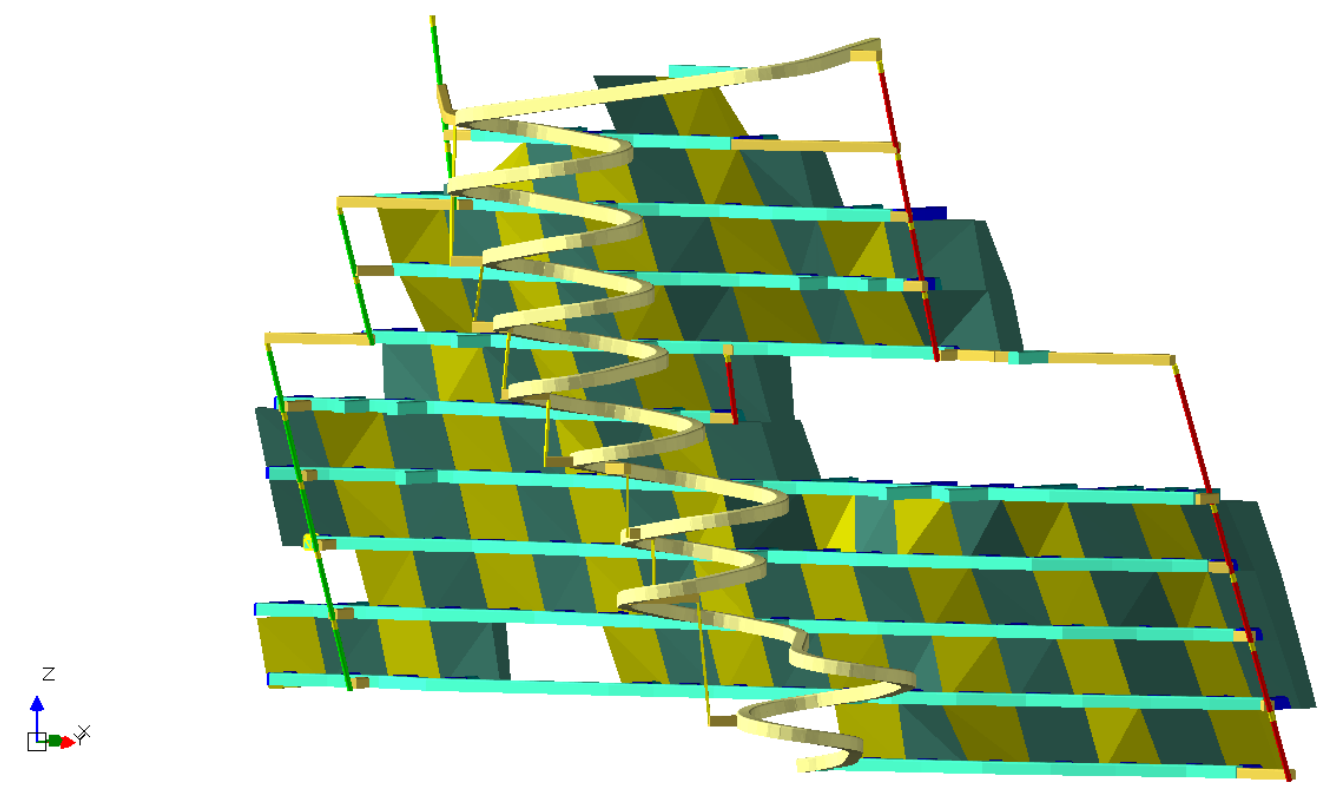

Figure 2 Mine design in CAD 


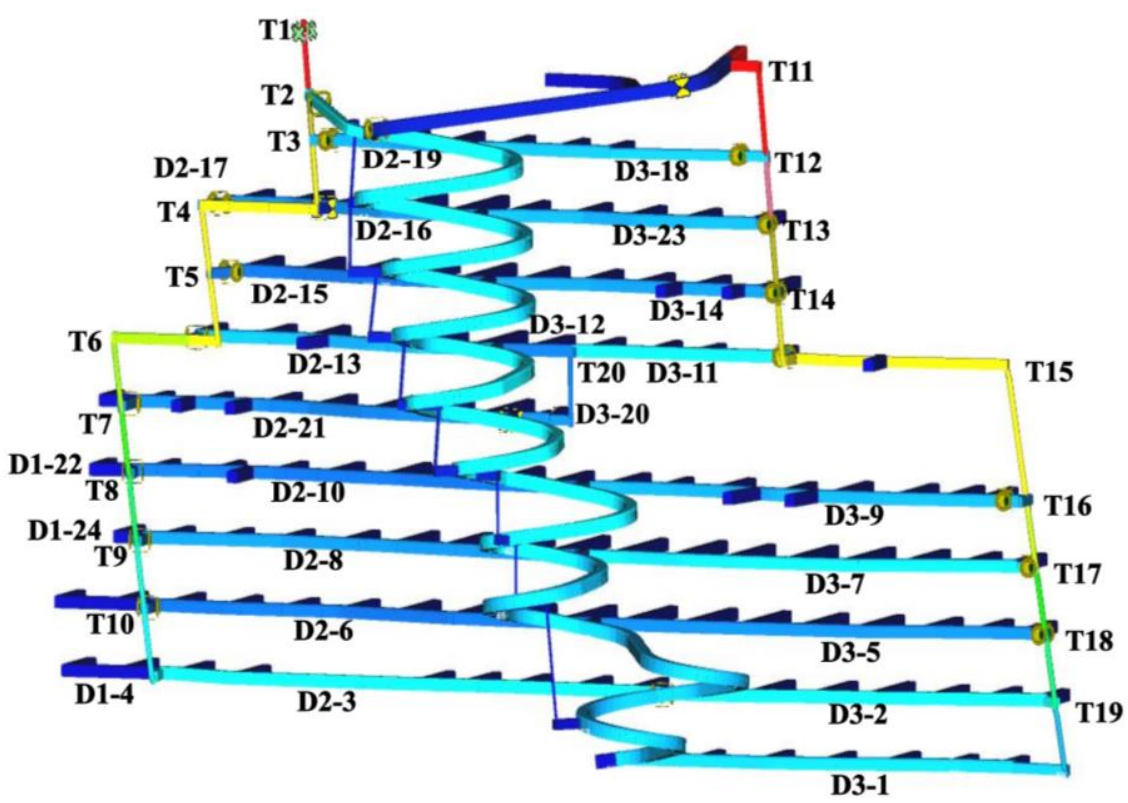

Figure 3 Mine layout in Ventsim showing locations of ventilation districts and trigger activities (' $D$ ' represents a ventilation district, and ' $T$ ' represents a trigger activity)

\subsection{Ventsim model}

The ventilation system for the mine, shown in Figure 3, is modelled in Ventsim, a three-dimensional ventilation network solver. Ventsim is able to perform both steady-state and dynamic airflow simulations and calculates airflow properties such as quantity, pressure, resistance, temperature, and heat (Widzyk-Capehart \& Watson 2001).

The airways were directly imported from Deswik.CAD. In some cases, manual corrections were needed to make connections between airways. The mine uses an exhaust ventilation system with two intakes and one return. Fresh air enters the mine through the series of raises on the right side, and the series of raises in the middle, which are temporary ventilation raises supporting fresh air to the ramp. This intake air supports the stoping and other mining activities. The contaminated air exits the mine through the return air raises, shown on the left in Figure 3.

Each stope is assigned to a ventilation district according to the minimum elevation value; that is to say, the stopes are in the same ventilation district as the crosscuts below them.

\subsection{SOT project}

SOT uses heuristics and a custom generic algorithm to maximise the NPV of long-term mine schedules. The schedules generated adhere to precedence constraints (dependencies) between the mining activities, and any given operational resource constraints. A user-provided financial model is needed for the assessment of the NPV of generated schedules.

The mine layout was imported into SOT, with activities including development, ventilation raises, ventilation drifts, temporary fresh ventilation raises, exhaust ventilation raises, ore crosscuts, waste crosscuts, ramps, drilling, mucking, filling, and curing. Just-in-time development was applied for all crosscuts, and a maximum lag was enforced between completion of mucking and the start of the corresponding fill activity.

For this study, the LHD equipment was not constrained, the development length capacity constraint was set to $8.53 \mathrm{~m}$ per day, and $6.10 \mathrm{~m}$ per day for a raisebore. No other equipment constraints were applied. The LHDs were associated with the mucking activities only. The financial model had a discount rate of $10 \%$, a nickel price of USD 10,384 per tonne, and a copper price of USD 5,798 per tonne. Operating and capital costs were applied to all activities on a per tonne or per metre basis. 


\subsection{Case study scenarios}

Two ventilation scenarios were created for comparison to a base case, which had the same financial model and the same operating constraints, but had no ventilation constraints. Scenario 1 provides sufficient airflow for six stoping activities on each level. Scenario 2 provides enough air for three stoping activities on each level. The logic behind the ventilation scenarios is that the number of stoping activities is constrained by the number of LHDs. However, the constraint on the number of LHDs is determined by the airflow availability in the ventilation district. For example, one LHD needs $18.88 \mathrm{~m}^{3} / \mathrm{s}$ of airflow to dilute the DPM concentration to under the regulatory limit. If there are $37.76 \mathrm{~m}^{3} / \mathrm{s}$ of airflow on a level, then two stopes can be mucked simultaneously on the level.

As shown in Figure 3, each level has between one and four ventilation raises. There are two sets of trigger activities (T1-T10 and T11-T19) that correspond to ventilation raises and three sets of ventilation districts (D1, D2, D3), as labelled in Figure 3.

Assumptions applied in this study are summarised as follows:

- Airflow in the stopes comes from the crosscuts intersected with and beneath the stopes. Therefore, the airflow availability on an upper-level crosscut intersected with a stope below will not affect activities in the stope.

- Stoping activities are constrained by the number of LHDs. A stope only needs one LHD to muck.

- Each LHD needs sufficient airflow to operate.

- No equipment constraints were imposed on activities related to production drilling, backfilling, and curing.

\subsection{Ventilation Constraint Module input}

For ventilation scenario 1, each ventilation district has an initial available airflow of $9.44 \mathrm{~m}^{3} / \mathrm{s}$. In this case, each of the 19 trigger activities (T2 to T20) increases the airflow by $28.32 \mathrm{~m}^{3} / \mathrm{s}$ in the associated ventilation district. Therefore, after the completion of all the trigger activities, $37.76 \mathrm{~m}^{3} / \mathrm{s}$ is available in each ventilation district, which is enough for two LHDs to work at the same time in each ventilation district.

For ventilation scenario 2, each ventilation district has an initial available airflow of $9.44 \mathrm{~m}^{3} / \mathrm{s}$. There are 19 unique trigger activities that each increase the airflow by $9.44 \mathrm{~m}^{3} / \mathrm{s}$ in the associated ventilation district. The total airflow in each ventilation district becomes $18.88 \mathrm{~m}^{3} / \mathrm{s}$, which is enough for an LHD mucking in each ventilation district.

\subsection{Results}

As discussed, three scenarios were created to validate the VCM and show the economic impacts of ventilation constraints in a schedule optimisation process. The base case had no ventilation-based equipment constraints. The VCM generated the ventilation scenarios with two sets of constraints. Ventilation scenario 2 has more strict ventilation constraints compared to those in ventilation scenario 1 . The schedule optimisation for each scenario was conducted in SOT.

For ventilation scenario 1 , at most two LHDs on each level of the three sets of ventilation districts operate at any point of the LOM. A screenshot from Deswik.CAD with stoping activities labelled as ' $A$ ' is shown in Figure 4. It can be seen that there is one stoping activity in the second set of ventilation districts and two stoping activities in the first and third set of ventilation districts.

From ventilation scenario 2 , at most one LHD on each level of the three sets of ventilation districts operates at any point of the LOM. A screenshot from Deswik.CAD with ongoing stoping activities labelled as ' $A$ ' is shown in Figure 4 . It can be seen that there is only one stoping activity in progress in each set of ventilation districts. 


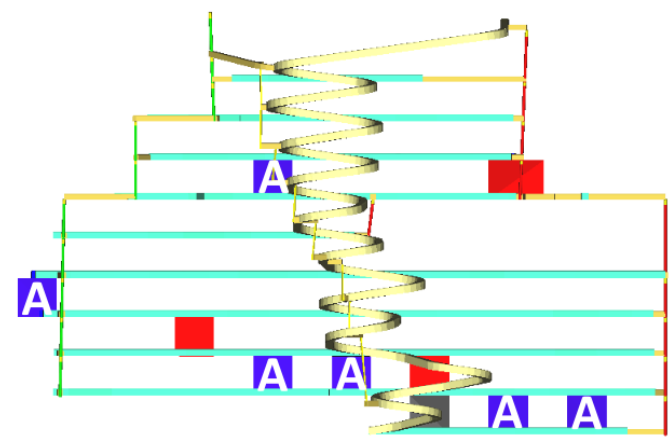

(a)

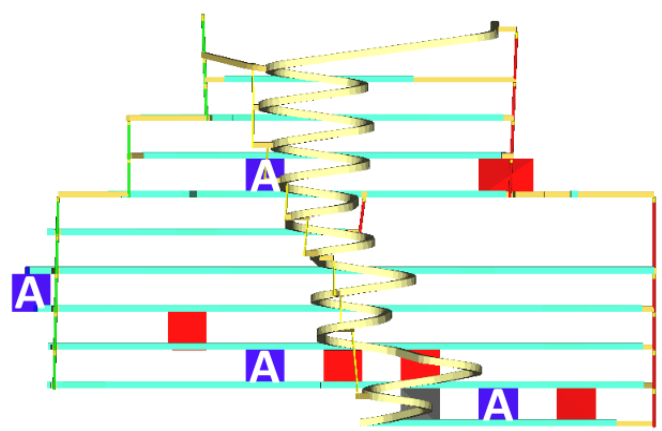

(b)

Figure 4 Active stopes (labelled 'A') at a point in the mine life for ventilation scenarios 1 (a); and, 2 (b)

For each of the ventilation scenarios, the LOM schedule was optimised in SOT, and the results are presented in Table 3.

Table 3 NPV of optimised schedules for each of the ventilation scenarios

\begin{tabular}{l|lll}
\hline & Base case & Scenario 1 & Scenario 2 \\
\hline NPV (USD millions) & 764.56 & 761.11 & 741.15 \\
\hline
\end{tabular}

As expected, the optimised schedule NPV decreased with stricter ventilation constraints. The base case, which did not use the VCM, had the highest NPV among the three scenarios. However, this schedule is likely to be infeasible from a ventilation standpoint. The reason for this is that ventilation is essential for diluting the harmful gases to under the legal limit in order to remain in operation. Therefore, a feasible and economically sound schedule, which will potentially generate different harmful gases, needs to take ventilation constraints into account when producing a long-term schedule. In addition, ventilation is a major cost for operating mines, which needs to be considered to accurately determine the expenditures associated with a particular schedule.

\section{$4 \quad$ Discussion and future work}

Airways of a ventilation network were directly exported from the mine design software to Ventsim for this study. This functionality saves much manual effort as compared to conventional practices. For a small number of cases, the airway identifier had to be manually corrected because of complexities in the mine geometry.

The initial airflow in each ventilation district and the changes in the airflow after the trigger activities are generated by the integration of the VCM with Ventsim. The VCM is able to generate feasible ventilation scenarios, which account for ventilation constraints in the schedule optimisation process. The VCM-generated ventilation scenarios are successfully integrated with SOT for optimisation of the NPV.

The ventilation scenarios only have LHD airflow requirements and do not explicitly account for other airflow requirements such as production drilling and development crews. Additional validation case studies will be performed using a real mine design with more complex ventilation constraints.

\section{Acknowledgement}

The authors thank Newmont, Vale Canada, Agnico Eagle, Deswik, Datamine, Chasm Consulting, and the UltraDeep Mining Network (UDMN) at the Centre for Excellence in Mining Innovation (CEMI) for their technical and financial contributions to the SOT+ project. The collaboration of Craig Stewart is gratefully acknowledged. 


\section{References}

Allen, CL \& Tran, TT 2011, 'Ventilation-On-Demand control system's impact on energy savings and air quality', Proceedings of the CIM Conference 2011, Canadian Institute of Mining, Metallurgy and Petroleum, Westmount.

Chasm Consulting 2016, Ventsim Visual User Guide, Chasm Consulting, Capabala.

Deswik Mining Consultants (Australia) Pty Ltd 2014, Deswik.CAD, Deswik Mining Consultants (Australia) Pty Ltd, Brisbane.

Fava, L, Saavedra-Rosas, J, Tough, V \& Haarala, P 2013, 'Heuristic optimisation of scheduling scenarios for achieving strategic mine planning targets', Proceedings of the 23rd World Mining Congress, Canadian Institute of Mining, Metallurgy and Petroleum, Westmount.

Hardcastle, S, Kocsis, C \& Lacroix, R 2007, 'Strategic mine ventilation control: A source of potential energy savings', Proceedings of the CIM Conference 2007, Canadian Institute of Mining, Metallurgy and Petroleum, Westmount, pp. 255-263.

Widzyk-Capehart, E \& Watson, B 2001, 'Agnew gold mine expansion, mine ventilation evaluation using Ventsim', in S Wasilewski (ed.), Proceedings of the 7th International Mine Ventilation Congress, Research \& Development Center for Electrical Engineering and Automation in Mining, Krakow, pp. 345-352. 